GHANA JOURNAL OF DEPARTMENT OF HEALTH, PHYSICAL EDUCATION AND RECREATION, SPORTS AND DANCE (GJOHPERSD)

Volume 10, Year 2017

A JOURNAL OF THE DEPARTMENT OF HEALTH, PHYSICAL EDUCATION AND RECREATION (HPER)

UNIVERSITY OF CAPE COAST

GHANA, WEST AFRICA 


\title{
FACTORS INFLUENCING TEENAGE PREGNANCY IN KOMENDA, EDINA, EGUAFO ABIREM MUNICIPALITY
}

\author{
Thomas Hormenu, Patrick Kwasi Akutu \& Stephen Oklu \\ Department of Health, Physical Education and Recreation, \\ University of Cape Coast \\ Email: thormenu@ucc.edu.gh
}

\begin{abstract}
Adolescents are the most important sexually active population in our societies, and given their size and characteristics, majority are exposed to early unplanned and unprotected sexual intercourse leading to unwanted pregnancy and sometimes unsafe abortions. Teenage pregnancy has become very common in the Ghanaian society, especially among adolescents at the Primary and Junior High School (JHS) levels of education. The purpose of this study was to assess the prevalence of teenage pregnancy in the Komenda, Edina, Eguafo Abrem Municipality in the Central Region of Ghana from 2012-2016. The study employed descriptive survey design to purposively sample teenage mothers and pregnant teenagers seeking antenatal and postnatal care at the Elmina Urban Health Centre and Ankaful Leprosy/General Hospital. Questionnaire and secondary data was collected and analyzed using simple frequencies and percentages. The finding revealed $25 \%$ prevalence of teenage pregnancy among the adolescents between 2012 and 2016. Poverty, peer pressure, and the influence of the media (electronic and social) were found to be the major risk factors to influence teenage pregnancy among the participants. Birth complications and school dropouts were the major consequences of teenage pregnancy among the participants. It was concluded that the high prevalence of teenage in the municipality could also lead to high presence of sexually
\end{abstract}


Factors Influence Teenage Prenancy Komenda, Edina, Eguafo Abirem Municipality

transmitted infections. It was therefore recommended that municipal assemblies establish trade schools as well as use successful indigenes as role models to increase students' ambition for the future and decrease their engagement in the sexual activities. Also, condom usage should be highlighted in the schools to help those who cannot abstain to use protection.

Keywords: Teenage pregnancy, Central region, adolescents 


\section{Introduction}

In recent past, adolescent pregnancy has become an important public health issue in a multitude of coastal dwellers in both developed and developing countries. Nonetheless, this menace of adolescent pregnancy is not a new occurrence in Ghana. The World Health Organisation [WHO] (2015) defines adolescent pregnancy as a teenage girl, usually within the ages of 13-19, becoming pregnant. Young girls becoming pregnant at such an early age have experienced lots of complications, hence, putting this people in danger of survival and proper development.

Children survival and development depend extensively on government and parental provision of a high standard of health, including nutrition; access to water and sanitation; child care; antenatal, post-natal and preventive care; family planning; and education on child health, nutrition and hygiene, sexual and reproductive health information, among other services (United Nations International Children's Emergency Fund [UNICEF], 2012). To address issues of adolescent sexual reproduction in the developing countries, UNFPA (2013) has postulated two distinctive objectives of relevance to the nations are; to address adolescent sexual and reproductive health issues, including unwanted pregnancy, unsafe abortion, and STIs, including HIV/AIDS, through the promotion of responsible and healthy reproductive and sexual behaviour and to substantially reduce all adolescent pregnancies. More specifically, it called for countries and the international community to protect and promote the right of adolescents to reproductive health education, information and care and greatly reduce the number of adolescent pregnancies.

WHO (2008) defines reproductive health as a state of complete physical, mental and social well-being, and not merely the absence of reproductive disease or infirmity. Reproductive health involves all of the reproductive processes, functions and systems at all stages of human life. This definition implies that people are able to have a satisfying and safe sex life. 
Factors Influence Teenage Prenancy Komenda, Edina,

Eguafo Abirem Municipality

According to WHO (2015), men and women have the right to be informed and to have access to safe, effective, affordable and acceptable methods of family planning that are not against the law. Reproductive health is a universal concern, but is of special importance for women particularly during the reproductive years. Reproductive health contributes enormously to physical and psychosocial comfort and closeness between individuals. Poor reproductive health is frequently associated with disease, abuse, exploitation, unwanted pregnancy, and death.

In Ghana, many people hold the view that the youth are healthy since they show low levels of illness compared to younger children and adults. However, a report by Ghana Statistical Service (2010) on the Ghana Demographic Health Survey in 2008 and other studies by Awusabo-Asare, Abane and Kumi-Kyereme (2004) revealed a higher magnitude of sexual and reproductive health problems of the youths, the most crucial being unprotected sex and risky sexual behaviour. According to Homans (2003), the habits and lifestyles that are established during this period have a profound effect on future health and development.

The 2015 Ghana Health Service Report indicates that more than 13,000 teenage girls got pregnant in the Central Region (GHS, 2016). This high prevalence is in line with the ranking of Central Region as the second highest region for the past three years (2013, 2014, and 2015). A 2014 report on teenage pregnancy in Ghana compiled by the Ministry of Gender, Children and Social Protection, observed that people living in the coastal areas particularly the Central and Greater Accra Regions, witnessed high rates of teenage pregnancy prevalence. About 231 of all teenage pregnancies were girls of age 14 and below. Meanwhile, 3576 of the teenage mothers are still single; and 283 married with their partners (Nyabor, 2017). Despite the extensive attention given to adolescent sexuality and teenage pregnancy in the past 30 years, many teenagers were still sexually active and getting pregnant (Van Eijk, 2007). 
There is a great cost to individuals, families and society when mere children have children of their own. Mwaba (2000) indicated that teenage pregnancy is more common amongst young people who have been disadvantaged and have poor expectations of either their education or the job market. The alarming figures released by Morake (2011) for the South African Provincial Education Department indicated that schoolgirl pregnancies have doubled in the past year, despite a decade of spending on sex education and Human Immunodeficiency Virus (HIV) and AIDS awareness. Premature sexual intercourse results in high rates of sexually transmitted diseases, HIV transmission, adolescent pregnancy and abortions (Mkhwanazi, 2006). The high rate of teenage pregnancy is not different in the Cape Coast Metropolis. The rate of teenage pregnancy in the Central Region has in the last 5 years seen a decline. However, officials of the Ghana Health Service reported that the current figure of 12,048 recorded in 2016 is still unacceptably high (Nyabor, 2017). Another report by the Central Region Health directorate confirmed that teenage pregnancy in the Region is very high. According to the report, teenage pregnancy especially among teenagers between the ages of 15-19 years was 14.7 percent between 2008 and 2009 (AsieduAddo, 2010). However, not much work has been done to elucidate the reasons for teenage pregnancy in KEEA Municipality. It is in the light of this that the study sought to investigate the factors influencing teenage pregnancy in the Komenda, Edina, Eguafo, and Abirem (KEEA) Municipality.

\section{Method}

Descriptive survey design was used to select 100 teenage mother or pregnant girls aged 13-19 years. Semi structured questionnaire was used for the collection of data from participants and the Director and Head, of Reproductive and Child Health Unit of the two hospitals in the Municipality. Secondary data was on the records of teenage pregnancy cases reported in the Municipality's Health Directorate from 2012-2016. The questionnaire for the teenagers was made up of three sections; A, B and C. Section A collected data on the demographic information of the respondent. 
Factors Influence Teenage Prenancy Komenda, Edina,

Eguafo Abirem Municipality

Section B consisted of the risk factors influencing teenage pregnancy. This section was made up of six items with the scale from one to four expressing Strongly Agree, Agree, Disagree and Strongly Disagree respectively. Section $C$ focuses on the consequences of teenage pregnancy. This section also consisted of five items with the scale from one to four expressing Strongly Disagree, Agree, Disagree and Strongly Disagree respectively. The items on this questionnaire were 18 items. The interview guide for the health staff was made up of two sections; sections A and B. Section A dwelt on the demographic information of the workers, Section B looked at teenage pregnancy prevention strategies being role out in the Municipality. Frequency and simple percentages were used to explain the data and to report on the prevalence of teenage pregnancy in the Municipality.

\section{Results}

\section{Research Question 1: What is the Prevalence of Teenage Pregnancy in the KEEA Municipality?}

This research question sought to find out the prevalence of teenage pregnancy in the KEEA Municipality. Secondary data was collected on the teenage pregnancy from 2012-2016 at the KEEA Municipality was analyzed to this question. The results are presented in Table 1. The records in Table 1 showed that from 2012-2016; there were 4,126 teenage pregnancy cases in the KEEA Municipality. The highest prevalence of teenage in the Municipality was recorded in 2012 with a total of 908 cases, representing 23\%. However, 2016 recorded the least cases of teenage pregnancy, totaling 739 and representing $18 \%$ of the teenage pregnancy cases. The table further revealed that most of the pregnant teenagers and mothers were between the ages of 1519 years, with a total of 4,032 representing (98\%) of teenage pregnancy cases recorded in the KEEA Municipality within the five years. It was also evident that the number of teenage pregnancy cases was diminishing as the years go by. 
Table 1: Prevalence of Teenage Pregnancy

\begin{tabular}{lccc}
\hline Year & $\begin{array}{c}\text { Age (Years) } \\
\mathbf{1 0 - 1 4}\end{array}$ & $\begin{array}{c}\text { Age (Years) } \\
\mathbf{1 5 - 1 9}\end{array}$ & Total \\
\hline 2012 & $24(26 \%)^{*}$ & $908(23 \%)$ & $932(23 \%)$ \\
2013 & $19(20 \%)$ & $837(21 \%)$ & $856(21 \%)$ \\
2014 & $22(23 \%)$ & $773(19 \%)$ & $795(19 \%)$ \\
2015 & $18(19 \%)$ & $775(19 \%)$ & $793(19 \%)$ \\
2016 & $11(12 \%)$ & $739(18 \%)$ & $750(18 \%)$ \\
\hline Grand Total & $\mathbf{9 4}$ & $\mathbf{4 , 0 3 2}$ & $\mathbf{4 , 1 2 6}$
\end{tabular}

Source: Elmina Urban Hospital, KEEA (2017).

Prevalence $=$ Total number of old cases + Total number of new cases $\times 100$

Population of female teenagers

Prevalence $=\underline{932+856+795+793+750} \times 100$

$$
16,828
$$

Prevalence $=\underline{4,126} \times 100$

$$
16,828
$$

Prevalence $=0.24519 \times 100$

Prevalence $=24.519$.

Therefore the current prevalence of teenage pregnancy in the KEEA Municipality is $25 \%$. From the Table 1 , we can conclude that among every 100 adolescent girls in the KEEA, 18 of them are pregnant and this finding post treats to public health in the area. Again, respondents indicated their first pregnancy occurred between $14-16$ years $(40 \%, n=40)$ while $32 \%(n=32)$ within $17-19$ years and $28 \%(\mathrm{n}=28)$ became pregnant within $11-13$ age range. Again, almost all the respondents $88 \%(n=88)$ reported that they were not married while $12 \%(\mathrm{n}=12)$ indicated that they were married. Moreover, a vast majority $72 \%(n=72)$ reported that the one who made them pregnant claimed responsibility of it while $28 \%(n=28)$ of the respondents indicated that the one who made them pregnant did not claim responsibility. Furthermore, most of the respondents $43 \%(n=43)$ reported that the men who got them pregnant were within the ages of 20-29 years, 33\% ( $n=33)$ indicated that the men who got them pregnant were 20 years and below, $23 \%(n=23)$ reported that the men who got them pregnant 
Factors Influence Teenage Prenancy Komenda, Edina,

Eguafo Abirem Municipality

were within the ages of 30-39 years while $1 \%(n=1)$ indicated that the man who got her pregnant falls in the 40 years and older category. Again, almost all the respondents $88 \%(\mathrm{n}=88)$ reported that they were not married while $12 \%(n=12)$ indicated that they were married after the pregnancy. The results further revealed that most of the respondents $60 \%(n=60)$ indicated that those who got them pregnant were workers in the town, while $25 \%(n=25)$ of those who got them pregnant were seniors at JHS/SHS, 9\% $(n=9)$ were school mate, $2 \%(n=2)$ and $4 \%(n=4)$ were seniors at university and teachers respectively.

Table 2: Background Characteristics of Respondents $(n=100)$

\begin{tabular}{lll}
\hline Variables & Frequency & Percentage (\%) \\
\hline Age of first pregnancy & 28 & 28.0 \\
$11-13$ & 40 & 40.0 \\
$14-16$ & 32 & 32.0 \\
$17-19$ & & \\
Are you married & 12 & 12.0 \\
Yes & 88 & 88.0 \\
No & & \\
Did the one who made you & & \\
pregnant & claim & \\
responsibility of it? & 72 & 72.0 \\
Yes & 28 & 28.0 \\
No & & \\
Who got you pregnant? & 9 & 9.0 \\
School mate & 25 & 25.0 \\
Senior at JHS/SHS & 2 & 2.0 \\
Senior at University & 4 & 4.0 \\
Teacher & 60 & 60.0 \\
Worker in the town & & \\
How old is the man who got & & \\
you pregnant? & 33 & 33.0 \\
Below 20 years & 43 & 43.0 \\
20-29years & 23 & 23.0 \\
30-39 years & 1 & 1.0 \\
Above 40 years & & \\
\hline
\end{tabular}


Source: Field Work (2017)

Research Question 2: What Risk Factors are Responsible for Teenage Pregnancy in the KEEA Municipality?

Research question two was posed to ascertain the various factors that influenced teenage pregnancy in the KEEA Municipality. Items in the section B of the research questionnaire catered for this. Respondents were asked to respond to a series of questions and their responses were presented in Table 3.

Results in Table 3 reveal that most of the respondents $60 \%$ $(n=60)$ indicated that peer pressure was a major risk factor that influenced teenage pregnancy in the municipality. Also, poverty $75 \%(n=75)$ was also found to be a risk factor to have influenced teenage pregnancy. The table further reveals media (electronic and social) $51 \%(n=51)$ also as factor that influence teenage pregnancy in the municipality.

Table 3: Risk Factors Influencing Teenage Pregnancy $(n=100)$

\begin{tabular}{|c|c|c|c|c|}
\hline & \multicolumn{2}{|c|}{ Agree } & \multicolumn{2}{|c|}{ Disagree } \\
\hline & F & $\%$ & $\mathbf{F}$ & $\%$ \\
\hline $\begin{array}{l}\text { Peer pressure } \\
\text { influence }\end{array}$ & 60 & 60.0 & 40 & 40.0 \\
\hline $\begin{array}{l}\text { Adequate knowledge } \\
\text { and use of } \\
\text { contraceptives }\end{array}$ & 16 & 16.0 & 84 & 84.0 \\
\hline $\begin{array}{l}\text { Adequate knowledge } \\
\text { about sex education }\end{array}$ & 64 & 64.0 & 36 & 36.0 \\
\hline Sexual abuse & 30 & 30.0 & 70 & 70.0 \\
\hline Poverty & 75 & 75.0 & 15 & 15.0 \\
\hline $\begin{array}{l}\text { Influence from the } \\
\text { media }\end{array}$ & 51 & 51.0 & 49 & 49.0 \\
\hline
\end{tabular}

Source: Fieldwork (2017).

Research Question 3: What are the Experienced Consequences of Teenage Pregnancy in the KEEA Municipality?

The intent of this research question was to find the consequences of teenage pregnancy in the KEEA Municipality. Respondents were asked to respond to a series of questions and their responses are presented in Table 4. In Table 4, majority of the 
Factors Influence Teenage Prenancy Komenda, Edina,

Eguafo Abirem Municipality

respondents $72 \%(n=72)$ reported that they experienced birth complications during delivery. The results further revealed that most of the respondents $93 \%(n=93)$ indicated that they had to drop out of school as a result of the teenage pregnancy. Again, majority of the respondents $54 \%(n=54)$ indicated that social and psychological stress were not consequences of teenage pregnancy. It was further shown in Table 4 that, most of the respondents 69 $(n=69)$ indicated that they experienced inadequate nutrition and financial hardship as impacts of teenage pregnancy. Again, majority of the respondents $51 \% \quad(n=51)$ reported that developmental disabilities were high in children born to teen mothers.

Table 4: Consequences of Teenage Pregnancy ( $n=100)$

\begin{tabular}{lllll}
\hline & \multicolumn{2}{c}{ Agree } & \multicolumn{2}{c}{ Disagree } \\
\cline { 2 - 5 } & F & $\mathbf{\%}$ & f & \% \\
Birth complications & 72 & 72.0 & 28 & 28.0 \\
School dropout & 93 & 93.0 & 7 & 7.0 \\
Psychosocial stress & 46 & 46.0 & 54 & 54.0 \\
Poverty & 69 & 69.0 & 31 & 31.0 \\
Developmental & 51 & 51.0 & 49 & 49.0 \\
disabilities & & & & \\
\hline \multicolumn{2}{l}{ Source Fieldwork (2017) }
\end{tabular}

Source: Fieldwork (2017)

Research Question 4: What Teenage Pregnancy Prevention

Strategies are Available within the KEEA Municipality?

This research question sought to find out the teenage pregnancy prevention strategies available within the KEEA Municipality? Interviews were granted to the heads of the Reproductive and Child Health Unit ( $\mathrm{RCH}$ ) has served for at least one year in the facility as well as the Senior Midwifery Officer who has also worked for seven years in the Elmina Urban hospital. Their responses are illustrated below:

Head of the RCH unit, aged 52 years said that:

"We have organised adolescent clubs in various schools in the Municipality. We visit these schools to deliver health seminars in other to educate adolescents on the consequences of teenage pregnancy as well as ways of preventing teenage pregnancy. We 
also provide contraceptives to teenage mothers who visit our facility, this however comes with a fee. We also give education at the maternity ward on the dangers of teenage pregnancy. Adolescent clubs are also formed in various communities in order to educate teenagers who are not going to school. I think that teenage pregnancy should be tackled from the homes; starting from parents, because parents do not have control over their children."

Senior Midwifery Officer, aged 50 years said that:

"Radio programme on the consequences of teenage pregnancy are organised by representatives in the Municipality, Talks are also given to teenage mother by midwives and other workers on how on prevent teenage pregnancy. Secondly, we educate pregnant teenagers on family planning whenever they come to the hospital."

From the responses of the interview, the first respondent reported that organising adolescents clubs in various schools and delivering seminars to educate teenagers on the consequences of teenage pregnancy are some of the preventive strategies that can be adopted in combatting teenage pregnancy. The first respondent also emphasised the importance of giving family planning education to first time teenage pregnant mothers who visit the hospital, this will help curb the rate of teenage pregnancy in the Municipality. Again, the first respondent highlighted the importance of parental control as a preventative strategy of curbing teenage pregnancy. Again, from the responses of the interview, the second respondent also reported that using the media as a platform to educate teenagers on the consequences of teenage pregnancy and educating teenagers on ways of preventing teenage pregnancy could help reduce the rate of teenage pregnancy.

\section{Discussion}

The findings of this study revealed that there was $25 \%$ prevalence of teenage pregnancy between 2012-2016 in the KEEA Municipality. This finding could be described as high in the region. The finding means that majority of girls in the municipality with the ages of 10-19 are at risk of becoming and putting the future of the municipality bleak. This outcome could be said to be consistent 
Factors Influence Teenage Prenancy Komenda, Edina,

Eguafo Abirem Municipality

with the report of Save the Children (2009) that annually 13 million children are born to women under age 20 worldwide and more than $90 \%$ are in developing countries. This possible reason for this similarity could be that today's adolescents are becoming too much sexually active. There is the need to start education that works on the risk factors to help prevent this issues before they become epidemic. The finding also agrees with Traffers (2003), who asserted that the highest rate of teenage pregnancy in the world is in Sub-Saharan Africa, where women tend to marry at an early age. The high prevalence of teenage pregnancy in the municipality could lead to high of complications associated with early pregnancy. Among these complications were birth complications, school dropout, financial challenges, inadequate nutrition as well as giving birth to children with developmental disabilities. Martin (2003) posits that young teenagers are more likely to give birth to an unhealthy, low birth weight infant because the girl's body may not be ready to support pregnancy. Sánchez and Solano (2003) also confirmed that inadequate nutrition during pregnancy is an even more marked problem among teenagers in developing countries.

On the issues of major risk factors of teenage pregnancy in the KEEA municipality, the study found that peer pressure was a risk factor that influenced teenage pregnancy. This finding corroborates with Buga, Amoko and Ncayiyana (1996) and Gyan (2013) who found out that most teenagers initiated sexual activity because of peer pressure. Adolescence is stage characterised with friendship; this socialization exerts great influence on the behaviours adolescents. Another significant issue that increases the fertility of peer influence is parental neglect and communication. Sex education are regarded as taboo in our part of the world couple with lack of communication between parents and their adolescents, hence, creating more rooms for media and peer influence. There is the need for parents; to develop that close connection with their adolescents and regularly discuss issues regarding sexual and reproductive health. Sexual abuse was not found as a risk factor that influenced teenage pregnancy in the municipality and this disagrees with Guttmacher Institute (2009), who found that girls 
who had sex before age 15 were coerced by males who on average were six years their senior. Poverty was a major risk factor that influenced teenage pregnancy and this confirms the findings of Kaiser (2000) and the South African Survey (2002) which indicated that $16 \%$ of a sample of 2000 teenagers confessed to having sex for money and $20 \%$ of teenage boys from the same sample indicated that they had given their girlfriends money in exchange for sex.

On the issue of whether birth complication was a consequence of teenage pregnancy, majority of the respondents indicated that they experienced birth complications during delivery. Births complications are bound to happen with most adolescents are still developing especially in their hips and uterus. Genobaga (2004) opines that teenage mothers are more likely to get complications during pregnancy such as pre-eclampsia, increase in blood pressure and early labour. The findings of this study further revealed that pregnant teenagers were unable to complete their education. This finding concurs with Luong (2008) who found that many adolescents who became pregnant do not complete high school because of the time off required for their pregnancy, recuperation, and child-care. The current study again revealed that psychosocial stress was not a consequence of teenage pregnancy. This is however not in line with Bartell (1999) who asserted that pregnant adolescents experience significant stress which could negatively impact their physical state if it went unmanaged.

It was found in this study that organising developmental and adolescent programmes to educate teenagers on the consequences of teenage pregnancy was one of the preventive strategies for reducing teenage pregnancy. This finding is consistent with Fletcher, Harden, Brunton, Oakley, and Bonell (2008), who asserted that organising youth and developmental programmes can be very effective in modifying behaviour, promoting safe sexual practices and reducing pregnancy rates among high-risk adolescents. Again it was found in this study that effective parental control should be employed by parents as a way 
Factors Influence Teenage Prenancy Komenda, Edina,

Eguafo Abirem Municipality

of helping to prevent teenage pregnancy. This finding is also in line with Swann, Bowe, McCormick and Kosmin (2003) who found that family outreach programmes and those programmes that included the adolescents' parents can be effective in preventing risky sexual behaviour and adolescent pregnancy. It was also evident in the findings of this study that giving sexual education on ways of preventing teenage pregnancy can help in curbing the rate of teenage pregnancy. This finding is in agreement with JAH (2008) who found that adolescents who received comprehensive sex education had lower risk of pregnancy than adolescents who received abstinence-only or no sex education. Again, Rozakis (1993) in his studies emphasized that with adolescents' knowledge of sex and sexuality they become aware of the advantages and disadvantages of indulging in sexual activities.

\section{Conclusions}

It was evidence that peer pressure, media and poverty were among some of the major factors that influenced teenage pregnancy in the Komenda, Edina, Eguafo, and Abirem Municipality. Birth complications and inability of teenagers to complete their education were some of the consequences of teenage pregnancy in the Municipality. Organising developmental and adolescent programmes, ensuring effective parental control and giving sexual education on ways of preventing teenage pregnancy are some of the preventive strategies that can assist in curbing this menace in the KEEA Municipality.

\section{Recommendations}

Based on the findings and conclusions, the following recommendations are made:

1. Parents of teenagers should build a strong bond of parentchild relationship with their children who have reached their adolescent stage and desist from pressuring their children for financial aid. Parents should also endeavour to exercise intense parental control over their children to avoid their children being victims of teenage pregnancy. 
2. It is recommended that the Ministry of Health in collaboration with the Planned Parenthood Association of Ghana (PPAG) and National Commission for Civic Education (NCCE) carry out educational programmes in communities to educate the youth on the challenges and dangers of teenage pregnancy and its effect on the individual, society and government at large. This could be done through dawn broadcasts, documentaries, drama and role play, advertisements on television, and mobile van film shows. Lorry parks, community centres, schools, and playgrounds could be targeted.

3. It is also recommended that there should be an establishment of reproductive health units that are friendly and ready to meet the health needs adolescents in the municipality.

\section{References}

Asiedu-Addo, S. (2010). 196 Pregnant girls in Central Region. Retrieved May 3, 2010 from www.graphicghana.com/society\%20and\%20lifestyle/pa ge. php?news

Awusabo-Asare, K., Abane, A. M., \& Kumi-Kyereme, A. (2004). Adolescent sexual and reproductive health in Ghana: A synthesis of research evidence. Occasional Report No. 13.

Buga, G. A. B., Amoko, D. H. A. \& Ncayiyana, D. J. (1996). Adolescent sexual behaviour knowledge and attitudes to sexuality among school girls in Transkei. South African East African Medical Journal, 73, 95 -100.

Fletcher, A., Harden, A., Brunton, G., Oakley, A., \& Bonell, C. (2008). Interventions addressing the social determinants of teenage pregnancy. Health Education, 108, 29-39.

Ghana Health Service (2015). 10,000 teenage pregnancies recorded in Ghana in 2015. Retrieved from Atinkaonline.com 
Factors Influence Teenage Prenancy Komenda, Edina,

Eguafo Abirem Municipality

Ghana Statistical Service (2010). Population and Housing Census Report. Accra.

Gyan, C. (2013). The effects of teenage pregnancy on the educational attainment of girls at Chorkor, a suburb of Accra. Journal of Educational and Social Research MCSER Publishing, Rome-Italy, 3(3), 53-60.

Homans, H. (2003). Youth Friendly Health Services: Responding to the Needs of Young People in Europe. United Nations Inter Agency Group (UNFPA/UNICEF/WHO) Consultant on Youth Friendly Services, Genève, 1-2.

Kaiser, H., J. (2000). Hot Prospects, cold facts: Potrait of young South Africa. Johannesburg: Sunday Times Publication.

Martin, R. C. (2003). Understanding sexuality. Chicago: World Book, inc. a Scott Fetzer company.

Mkhwanazi, N., (2006). Teenage pregnancy and gender. Department of Anthropology, University of Cambridge.

Morake, A., 2011, Factors associated with Teenage Pregnancy in Limpopo Province. Government Printers, Polokwane.

Mwaba, K., (2000). Perceptions of teenage pregnancy among South African adolescents. Health Gesondheid 5(3), $30-35$.

Nyabor, J. (2017). Teachers, drivers impregnate 977 teenagers in

Central Region. Retrieved from

https://citifmonline.com/2017/02/27

Swann, C., Bowe, K., McCormick, G., \& Kosmin, M. (2003). Teenage pregnancy and parenthood: A review of reviews. London, UK: Health Development Agency.

Traffers, P. E. (2003). Teenage pregnancy, a worldwide problem. Retrieved from http/www.marchofdimes.com

UNFPA. (2013). Adolescent pregnancy: A review of the evidence. New York: UNFPA

Van Eijk, R.T., (2007). Factors contributing to teenage pregnancies in Rarotonga, United Nations Population Fund (UNFPA), Avarua.

WHO, (2008). The reproductive health library. Retrieved from apps.who.int/rhl/en/index.html 
WHO, (2015). Guidelines on preventing early pregnancy and poor reproductive outcomes among adolescents in developing countries. Geneva: World Health Organization.Retrievedhttp://whqlibdoc.who.int/publicat ions/2011/9789241502214_eng.pdf 